\title{
HERMAPHRODITISM IN COCONUT COLLECTIONS OF ViSCA, LEYTE, PHILIPPINES
}

By

T. C. Nunez*

\begin{abstract}
Bisexual button-like flowers were found in the dwarf cultivars Albuera, Catigan, Coconino, Lingkuranay, Malayan Red, Malayan Yellow and Tacunan as well as in Baybay Tall in varying frequencies. These hermaphrodites differed in size, possessed varying number of fully developed anthers that contained pollen with $46.4-84.1 \%$ fertility. knong the big hermaphrodites, their distinct characteristics are partly exposed ovary at inflorescence opening and earlier stigmatic receptivity compared with the normal buttons.
\end{abstract}

\section{INTRODUCTION}

Coconut flowers are normally unisexual but the existence of bisexual flowers or hermaphrodites wasearlier reported in India and was later confirmed in the dwarf population Nias Yellow in Indonesia by Davis, et al. (1986). Hermaphrodites were recently encountered too in the Philippine coconut materials Baybay Tall (BAY) and Tacunan (TAC) leading to suspicion that bisexual flowers could possibly be present in the other coconut populations in the country. Since, these hermaphrodites are very likely culprit in the production of illegitimates even in very strict controlled pollination in coconut, it is necessary that a way of properly identifying them in the different cultivars being used for hybridization be developed for timely removal of these possible contaminants thus enhancing the success of the expensive and tedious coconut hybridization work.

\section{METHODOLOGY}

Nine coconut cultivars in the germplasm of the Regional Coconut Research Center, Visayas State College of Agriculture, Baybay, Leyte, Philippines were used in the study. These cultivars were collected from UP at Los Banos, PCA Zamboanga and Leyte and Cebu provinces. Twenty palms each of the more homogenous dwarfs namely; Albuera (ALD), Coconino (CNO), Catigan (CAT), Dumano (DUM), Lingkuranay (LKY), Malayan Red (MRD) and Malayan Yellow (MYD), 18 trees of Tacunan (TAC) and 50 trees of Baybay Tall (BAY) which is considered to be more heterogeneous than the dwarfs were randomly chosen and observed for the presence of bisexual flowers. At least nine consecutive inflorescence of each palm were studied at initial opening. The polar and equatorial diameters of each button/button-like structure were measured using a dial caliper. Then, each was examined for the presence of stamen (S) indicating hermaphroditism. Distinct features of hermaphrodite flowers were also noted. 
*Associate Professor, Regional Coconut Research Center, Visayas State College of Agriculture (VisCA), Baybay, Leyte, Philippines.

Fully developed anther samples were taken from the bisexual flowers and tested for pollen fertility. Pollen fertility test was done using $12 \mathrm{KI}$ as stain. Under a microscope round, full and well stained pollen grains were counted as fertile while shriveled, empty or those with partly stained cytoplasm were considered sterile. Ten microscopic fields per sample were examined in the fertility test.

\section{RESULTS AND DISCUSSION}

\section{Extent of Occurrence}

Bisexual flowers were found in both dwarf and tall cultivars studied in varying frequencies. Ninety percent $(90 \%)$ of CNO trees, $70 \%$ of MYD, $68 \%$ of BAY, $55 \%$ of DUM, $40 \%$ of ALD and CAT, $39 \%$ of TAC, $25 \%$ OF MRD and 15\% OF LKY bore hermaphrodite flowers (Table 1). Similar to the findings of Davis, et al. (1986) in Nias Yellow variety, hermaphroditism was absent in other trees most probably due to the absence of the gene for the aforesaid character.

Not all inflorescences of hermaphrodite-bearing trees bore bisexual flowers. Further, out of at least 2,250 buttons of a cultivar, only $0.10 \%$ to $2.18 \%$ were hermaphrodites. The highest frequency was found in the tall BAY, followed by CNO, TAC, MYD, DUM, MRD, ALD and LKY. The latter had the least occurrence of hermaphroditism both in terms of number of bearing trees and percentage of bisexual flowers among buttons/ button-like structures.

TabLe 1. Occurrence of hermaphrodite flowers in nine cuLtivars

\begin{tabular}{|l|c|c|c|c|c|c|l|}
\hline $\begin{array}{c}\text { Culti- } \\
\text { Var }\end{array}$ & $\begin{array}{c}\text { Sample } \\
\text { Tree }\end{array}$ & $\begin{array}{c}\text { Herma- } \\
\text { Phrodite } \\
\text { Bearing } \\
\%\end{array}$ & $\begin{array}{c}\text { Observed } \\
\text { Inflo- } \\
\text { Rescence }\end{array}$ & $\begin{array}{c}\text { Button } \\
\text { Coconut }\end{array}$ & $\begin{array}{c}\text { Herma- } \\
\text { phrodites } \\
\text { No }\end{array}$ & $\%$ & Remarks \\
\hline ALD & 20 & 40 & 203 & 3400 & 9 & 0.26 & Hermaphrodites \\
\hline BAY & 50 & 68 & 512 & 7252 & 158 & 2.18 & Usually had partly \\
\hline CAT & 20 & 40 & 220 & 3271 & 11 & 0.34 & Exposed ovary and \\
\hline CNO & 20 & 90 & 193 & 6997 & 86 & 1.23 & Exhibited stigmatic \\
\hline DUM & 20 & 55 & 206 & 3309 & 15 & 0.45 & Respectivity earlier \\
\hline LKY & 20 & 15 & 227 & 4081 & 4 & 0.10 & Than normal \\
\hline MRD & 20 & 25 & 185 & 2877 & 6 & 0.21 & Buttons \\
\hline MYD & 20 & 70 & 192 & 3925 & 38 & 0.97 & \\
\hline TAC & 18 & 39 & 189 & 2250 & 24 & 1.07 & \\
\hline
\end{tabular}

\section{Characteristics}

One problem with hermaphrodites is their close semblance to the normal buttons. They are button-like except perhaps for the size of majority of them which was described by Davis, et al. (1986) as intermediate between female and male flowers. Thus, they were usually treated as female flowers and retained during emasculation specifically those located at the base of spikelets where the normal buttons usually are. These are the potential sources of unwanted pollen. Small hermaphrodites were usually interspersed among the florets and may possibly be cut with the male flowers during emasculation. 
Results obtained at the Regional Coconut Research Center confirmed that $100 \%$ of the small button-like structures which were usually found in BAY and CNO were bisexual flowers (Fig. 1). Hence, abnormally small button-like flowers should be removed during emasculation. However, big hermaphrodites were found which were almost as big as the average normal female flowers. MYD even produced hermaphrodites measuring $22.7 \mathrm{~cm}$ at the polar and $17.6 \mathrm{~cm}$ at the equatorial parts (Table 2) which were bigger than the mean size of its normal buttons which measured $17.5 \mathrm{~cm}$ and $21.1 \mathrm{~cm}$ at the polar and equatorial diameters, respectively. Likewise, the big bisexual flowers of BAY, CNO and DUM were very close to the mean size of their normal buttons. These big type of bisexual flowers therefore, could hardly be distinguished from the normal buttons based on size. Interestingly, observation revealed distinguishing characteristics of the bisexual flowers regardless of size. At inflorescence opening, the hermaphrodites could be identified by the early exposure of the ovary due to underdeveloped corolla (Fig. 2a). More often, one or two stamens were also exposed where the ovary was not covered making identification easier (Fig. 2b). Underdevelopment of the corolla is a dependable basis for identifying big hermaphrodites. These hermaphrodite flowers also reached stigmatic receptivity earlier than the normal buttons.

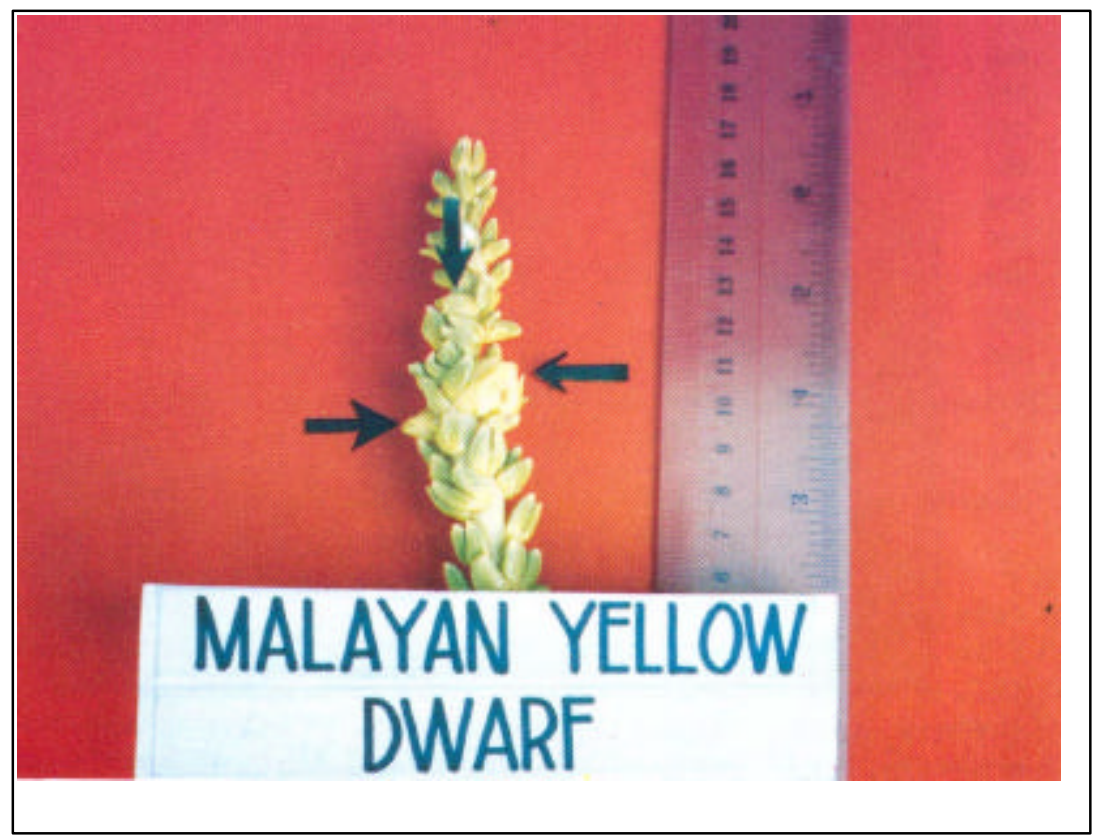

Fig. 1 Small hermaphrodite flowers among normal male florets

Table 2. Size (mm) of buttons and hermaphrodites of nine coconut cultivars

\begin{tabular}{|l|c|c|c|c|c|c|}
\hline \multirow{3}{*}{ Cultivar } & \multicolumn{2}{|c|}{ Mean size of buttons } & \multicolumn{3}{c|}{ Range of size of Hermaphrodites } \\
\cline { 2 - 7 } & \multicolumn{3}{|c|}{} & \multicolumn{2}{c|}{ Biggest } & \multicolumn{2}{c|}{ Smallest } \\
\cline { 2 - 7 } & $\begin{array}{c}\text { Polar } \\
\text { Diameter }\end{array}$ & $\begin{array}{c}\text { Equatorial } \\
\text { Diameter }\end{array}$ & $\begin{array}{c}\text { Polar } \\
\text { Diameter }\end{array}$ & $\begin{array}{c}\text { Equatorial } \\
\text { Diameter }\end{array}$ & $\begin{array}{c}\text { Polar } \\
\text { Diameter }\end{array}$ & $\begin{array}{c}\text { Equatorial } \\
\text { Diameter }\end{array}$ \\
\hline ALD & 20.0 & 24.0 & 14.2 & 16.2 & 10.5 & 116 \\
BAY & 20.9 & 25.2 & 19.8 & 23.7 & 7.6 & 8.4 \\
CAT & 21.5 & 25.4 & 15.9 & 19.0 & 12.6 & 13.4 \\
CNO & 19.8 & 23.6 & 19.2 & 21.0 & 8.6 & 9.9 \\
DUM & 20.1 & 24.4 & 17.3 & 23.2 & 13.4 & 15.9 \\
\hline
\end{tabular}




\begin{tabular}{|l|c|c|c|c|c|c|}
\hline LKY & 19.9 & 23.4 & 15.8 & 16.2 & 14.4 & 14.7 \\
MRD & 20.7 & 25.8 & 18.7 & 20.4 & 13.2 & 14.9 \\
MYD & 17.5 & 21.1 & 22.7 & 17.6 & 8.8 & 11.2 \\
TAC & 22.8 & 27.6 & 17.6 & 24.9 & 10.4 & 9.5 \\
\hline
\end{tabular}

\section{Number of Anthers and Pollen Fertility}

The hermaphrodite flowers examined possessed varying number of fully developed anthers ranging from 1 to 6 in BAY, CAT, CNO, DUM and MYD; 2 to 6 in ALD and TAC, 1 to 5 in MRD and 2 to 5 in LKY (Table 3). Other stamens lack anthers while others had underdeveloped anthers. Small hermaphrodites tended to have more fully developed anthers than the bigger ones while very small ones almost always have six fully developed anthers (Fig. 3).

Fully developed anthers from the hermaphrodite flowers contained pollen with varying degrees of fertility. Pollen fertility varied within a tree, among trees of a cultivar and among cultivars. Initial study showed the highest fertility percentage in ALD with $84.1 \%$ fertile pollen and the lowest in LKY with $46.4 \%$ fertile pollen. Others had more than $60 \%$ fertile pollen. Although pollen viability is a closer measure of the ability of pollen to effect fertilization, the aforementioned percentages of pollen fertility are also indicative of the, high probability of effective fertilization by pollen from hermaphrodite flowers which is unwanted in controlled hybridization work.

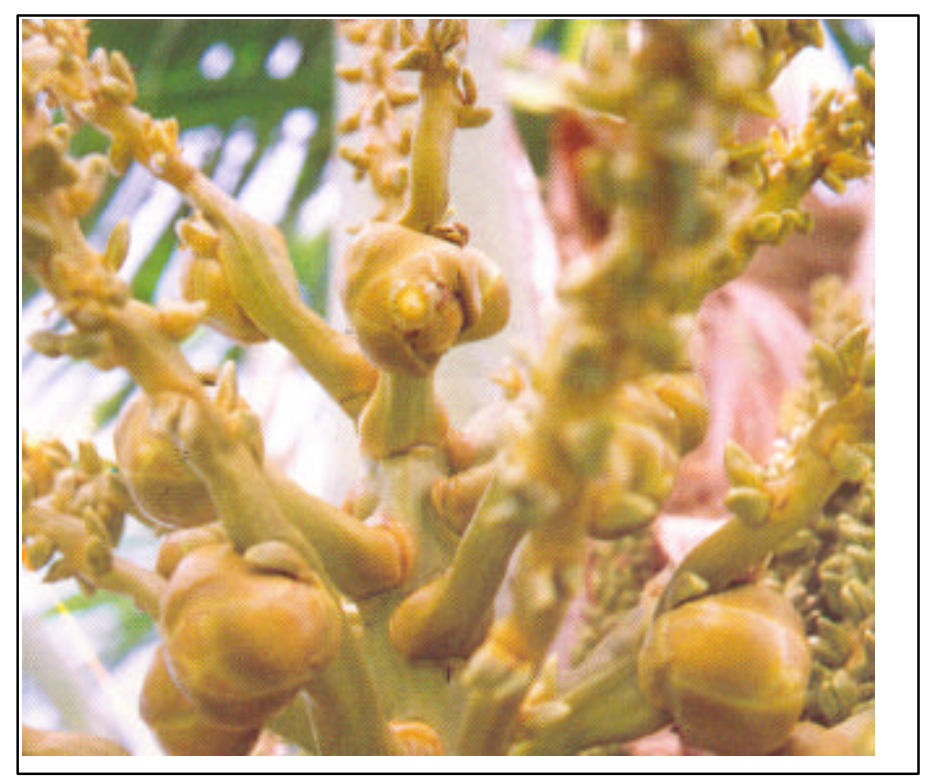

Fig. 2a A big hermaphrodite flower (center) with partly exposed ovary surrounded By normal buttons

Table 3. Number of fully developed anthers and pollen fertility of hermaphrodites from nine coconut cultivars

\begin{tabular}{|l|c|c|}
\hline \multicolumn{1}{|c|}{ Cultivar } & $\begin{array}{c}\text { Range of Anther } \\
\text { No. per Hermaphrodite }\end{array}$ & $\begin{array}{c}\text { Mean Pollen Fertility } \\
\text { Percentage }\end{array}$ \\
\hline ALD & $2-6$ & 84.1 \\
BAY & $1-6$ & 79.9 \\
CAT & $1-6$ & 70.9 \\
CNO & $1-6$ & 65.3 \\
\hline
\end{tabular}




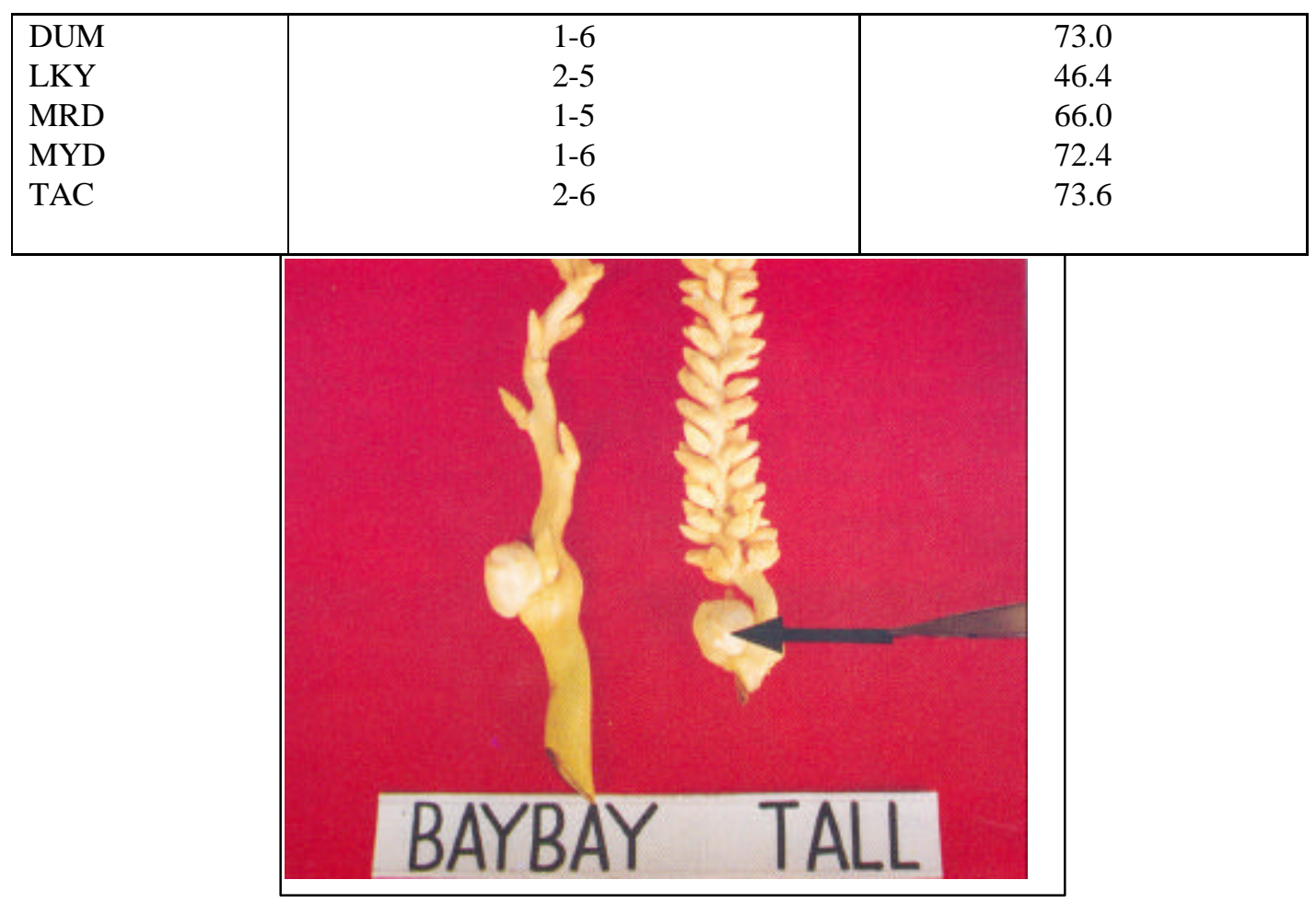

Fig. $2 b$ Exposed anther of a hermaphrodite flower

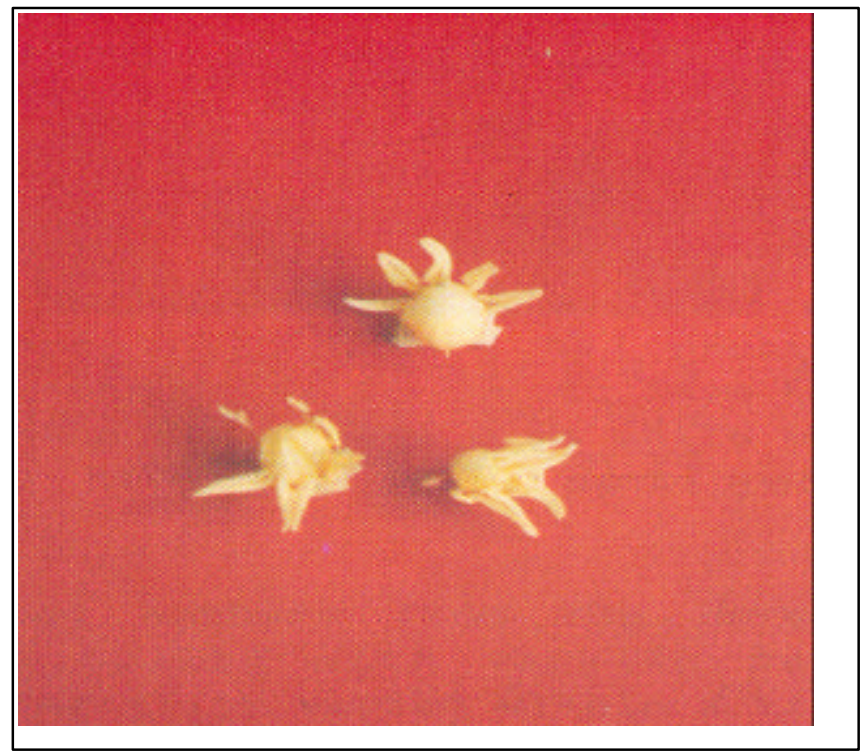

Fig. 3 Small hermaphrodites with four and five fully Developed anthers each (calyx \& corolla removed)

\section{CONCLUSION}

Hermaphrodite coconut flowers were found in all cultivars studied both in the tall and dwarf warranting a similar investigation in other potential coconut breeding materials to be used as 
seedparents. Results of this initial study showed that hermaphrodites can be visually identified based on characteristics that may prove to be common among bisexual flowers of all cultivars.

\section{ACKNOWLEDGMENT}

The author is thankful to Mr. Reynaldo Lastimado and Ms. Raquel Rosal for their help in data gathering and to Ms. Lucita S. Bravo for her assistance in preparing the manuscript.

\section{REFERENCE}

DAVIS, T.A., DARWIS, S. N. and SUDASRIP, H. 1986. Coconut Research Institute, Manado, Indonesia. In Coconuts Today Volume 4 No. 1 pp. 92-112. 